\title{
Novel starter cultures Virgibacillus spp. selected from grasshopper sub shrimp paste to inhibit biogenic amines accumulation
}

\author{
Yirui Zhao ${ }^{1,2}$, Xue Sang ${ }^{1,2}$, Hongshun $\mathrm{HaO}^{2}$, Jingran $\mathrm{Bi}^{1,2}$, Gongliang Zhang ${ }^{1,2}$ and Hongman $\mathrm{Hou}^{1,2^{*}}$ (0)
}

\begin{abstract}
Controlling the content of biogenic amines (BAs) is critical to guarantee the safety of fermented aquatic products. The degradation characteristics and application potential of amine-negative starter cultures (Virgibacillus halodenitrificans CGMCC 1.18601: G25, Virgibacillus pantothenticus CGMCC 1.18602: G38) screened from grasshopper sub shrimp paste (Gssp) were studied. The enzymes of the two strains G25 and G38 that degrade BAs were amine oxidases (AOs) located on their respective cell membranes. The conditions that promoted the AO activity of Virgibacillus spp. were $\mathrm{NaCl}$ concentrations $5-10 \%$, temperature $37^{\circ} \mathrm{C}, \mathrm{pH} 7.0$ and ethanol concentrations $0-2 \%$. Safety assessments (antibiotic susceptibility, biofilm activity and hemolytic activity) indicated that Virgibacillus spp. do not present a risk to human health, and this isolate can be confidently recommended as safe starter cultures for the food industry. Then, the two strains were cultured separately as starters and applied to the Gssp to analyze their influence on the flavor and quality of the product. As far as the bad flavors in Gssp such as sulfur-organic and sulf-chlor were concerned, the response values in the starter groups by G25 and G38 were significantly reduced by 39\% and 65\%, respectively. For the ability of strains to degrade BAs in Gssp, G25 degraded $11.1 \%$ of histamine, $11.3 \%$ of tyramine, $15.5 \%$ of putrescine and $4.1 \%$ of cadaverine; G38 significantly degraded $10.1 \%$ of histamine, $21.8 \%$ of tyramine, $18.1 \%$ of putrescine and $5.0 \%$ of cadaverine. These results indicated that the selected species could be used as starter cultures for the control of BA accumulation and degradation in Gssp.
\end{abstract}

Keywords: Grasshopper sub shrimp paste, Starter cultures, Amine oxidases, Degradation of biogenic amines, Safety assessment

\section{Introduction}

For many years, fermented aquatic products have been very popular in Asia. They have a unique taste and their special flavor makes them a flavoring ingredient widely used in many cuisines. These products are highly salted, and fermentation normally takes several months (3-9 months), and the flesh may liquefy or form a paste during the process (Phewpan et al. 2019; Xinran et al. 2020). Some of these products include Nuoc-Mam

\footnotetext{
*Correspondence: houhongman@dlpu.edu.cn

1 School of Food Science and Technology, Dalian Polytechnic University, No.1, Qinggongyuan, Ganjingzi District, Dalian 116034, China

Full list of author information is available at the end of the article
}

(Nakano et al. 2018) of Vietnam and Cambodia, Nam-Pla (Natteewan et al. 2011) of Thailand, and Patis (Orejana and Liston, 2010) of the Philippines.

However, Asian fermented aquatic products pose a series of security risks. The most problematic safety issues are the presence of biogenic amines (BAs) (Spano et al. 2010; Kim et al. 2019). Poisoning from the ingestion of foods containing high levels of BAs has historically been referred to as scombroid poisoning because of the frequent association of this illness with the consumption of spoiled scombroid fish, such as mackerel and tuna. Additionally, anchovies, herrings, pilchards, sardines, shrimp, and some shellfish have been implicated in BA poisoning in Japan, Indonesia, and Sri Lanka, where 
food poisoning from aquatic products consumption is reported more often. Public health officials in many other countries acknowledge that BA poisoning occurs, but it is not officially required to be reported.

BAs are a group of low molecular weight organic compounds with biological activity and they contain nitrogen (Gardini et al. 2016). The most important BAs in fermented products are histamine (HIM), tyramine (TYR), putrescine (PUT) and cadaverine (CAD). They are mainly produced by decarboxylation of amino acids (Tan et al. 2019). Currently, there are many ways to control the content of BAs. The main measures are as follows: (1) reducing the level of amino acids in the precursor (Lorenzo et al. 2017); (2) inhibiting the growth of putrefactive microorganisms (Latorre Moratalla et al. 2007); and (3) using a strain that does not produce amino acid decarboxylase as a fermentation agent (Naila et al. 2010). When none of these methods can effectively reduce the BA content, the methods of adding microorganisms or BA-degrading enzymes can be used.

Many scholars have degraded BAs in food by inoculating microorganisms that do not have amino acid decarboxylase activity but have amine oxidase (AO) activity (Zaman et al. 2011). Degradation of BAs by AOs produced by some microorganisms is currently considered to be the most promising way to remove BAs from foods (Miguel et al. 2014; Callejón et al. 2014, 2016). Studies have shown that Lactobacillus plantarum ZY-40 can reduce the content of PUT and CAD in silver carp intestine by more than $70 \%$ (Zhang et al. 2013). Staphylococcus epidermidis $\mathrm{R} 11$ with $\mathrm{AO}$ activity in fermented sausage could help reduce HIM accumulation (Wang et al. 2015). Lactobacillus plantarum (ACBC271) and Staphylococcus xylose (CGMCC1.8382) were used as mixed fermentation agents to reduce the content of BAs in rice wine by $20.4 \%$ (Xiaole et al. 2018). Lactobacillus curvatus G-1 can degrade all BAs in Chinese bacon by more than $40 \%$ (Lu et al. 2018). Published researches gave evidence that Vergibacillus halodenitrificans can degrade histamine (Naila et al. 2012). Selecting proper starter cultures, optimizing fermentation conditions, and adding appropriate additives can help reduce BA formation and improve the quality of fermented products (Lee et al. 2012). Therefore, the screening of strains with AO activity as starters are of great significance for inhibiting the accumulation of BAs.

Grasshopper sub shrimp paste (Gssp) (Sang et al. 2020a) is a famous traditional fermented aquatic product in China. The grasshopper sub shrimps used in the production of the paste are mainly distributed around the Bohai Sea, where seawater and freshwater come into contact. Due to its unique flavor and excellent nutritional value, Gssp has been popular with a long history in
China. However, it is traditionally manufactured by natural fermentation, which tends to lack quality and safety controls, and leads to the accumulation of BAs through microbial contamination.

In this study, we tried to isolate strains with biogenic amine (BA) degradation ability from grasshopper sub shrimp paste (Gssp) and defined it as non-BA producing. Among them, Virgibacillus halodenitrificans CGMCC 1.18601 (G25) and Virgibacillus pantothenticus CGMCC 1.18602 (G38) showing the strongest BA degradability were selected. Furthermore, the isolates were evaluated in terms of their potential as protective starter cultures based on a safety assessment. Then, we finally determined whether they can improve the bad flavors of the Gssp fermentation, and evaluated whether these strains are suitable for the preparation of Gssp.

\section{Materials and methods}

\section{Samples and chemicals}

BA standards, including histamine (HIM), tyramine (TYR), putrescine (PUT) and cadaverine (CAD), were purchased from Aladdin; acetonitrile and methanol were purchased from Spectrum Chemical; and L-histidine hydrochloride, L-tyrosine disodium salt, L-ornithine hydrochloride, and L-lysine hydrochloride were purchased from BBI. Acetonitrile and methanol were chromatographic grade, while all of the other chemicals were analytical grade.

\section{Strains and growth conditions}

The research object came from 103 species kept in the laboratory, which were isolated from Gssp. The strains were grown in Luria-Bertani (LB) broth or on LB agar medium at $37^{\circ} \mathrm{C}$ for $24 \mathrm{~h}$. The strains were subcultured in LB broth for $24 \mathrm{~h}$, and then streaked on LB agar medium, before being cultivated in LB broth for $24 \mathrm{~h}$ before use.

\section{Screening of strains Decarboxylase activity}

The decarboxylase activity of the strains was measured by culturing the strains in a liquid decarboxylase medium containing L-histidine hydrochloride, L-tyrosine disodium salt, L-ornithine hydrochloride and L-lysine hydrochloride. The color change of the medium at $48 \mathrm{~h}$ was monitored at $37{ }^{\circ} \mathrm{C}$. Purple indicates a positive decarboxylase reaction, while yellow indicates it is negative (Eom et al. 2015).

\section{AO activity}

The AO test was carried out for the decarboxylase negative bacteria. The test method was as follows (Cheng et al. 2020): dip a white clean filter paper into the colony, add a drop of $1 \%$ dimethyl phenylenediamine hydrochloride 
solution, and then the solution turns pink and the color gradually deepens. After adding a drop of $1 \% \alpha$-naphthol ethanol solution, the positive color turned blue within half a minute, and the negative color was unchanged within two minutes. Positive cultures were the desired strains.

\section{Evaluation of $B A$ degradability}

To evaluate the BA degrading activity of the amino acid decarboxylase negative and $\mathrm{AO}$ positive strains (Xu et al. 2016), the seed solution was inoculated into LB medium at a $1 \%$ inoculation volume, and then cultured at $37{ }^{\circ} \mathrm{C}$ and $150 \mathrm{r} / \mathrm{min}$ for $24 \mathrm{~h}$. The cells were collected by centrifugation at $4000 \mathrm{~g}$ for $10 \mathrm{~min}$ at $4{ }^{\circ} \mathrm{C}$, washed twice with $0.05 \mathrm{~mol} / \mathrm{L} \mathrm{pH} 7.0$ phosphate buffer solution, and then the bacteria were resuspended at four concentrations of $500 \mathrm{mg} / \mathrm{L}$ BAs (HIM, TYR, PUT and CAD) in $0.05 \mathrm{~mol} / \mathrm{L}$ phosphate buffer with $\mathrm{pH}=7.0$, adjusting the bacterial suspension concentration to $\mathrm{OD}_{600 \mathrm{~nm}}=0.8$, and then cultured at $37{ }^{\circ} \mathrm{C}$ and $150 \mathrm{r} / \mathrm{min}$ for $48 \mathrm{~h}$. The phosphate buffer solution containing BAs without any bacterial cells was kept under the same conditions for $48 \mathrm{~h}$ as a control group. After that, high-performance liquid chromatography (HPLC) was performed to quantify the BAs and to calculate the degradation rates of each BA by applying Formula 1.

$$
\text { Degradation rates }(\%)=\left(\mathrm{W}_{0}-\mathrm{W}_{1}\right) / \mathrm{W}_{0} * 100 \%
$$

Annotate: $\mathrm{W}_{0}$-The content of biogenic amines in the control group, $\mathrm{mg} / \mathrm{kg}$;

$\mathrm{W}_{1}$-The content of biogenic amines in the experimental group, $\mathrm{mg} / \mathrm{kg}$.

\section{Degradation of BAs under different conditions}

\section{Effects of $\mathrm{NaCl}$ concentration on the $\mathrm{BA}$ degradation rates}

The washed cells were resuspended in $0.05 \mathrm{~mol} / \mathrm{L}$ phosphate buffer ( $\mathrm{pH} 7.0)$ supplemented with $500 \mathrm{mg} / \mathrm{L}$ of each BA. The cell concentration was adjusted to $\mathrm{OD}_{600}$ $\mathrm{nm}=0.8$. The $\mathrm{NaCl}$ concentration adjusted to achieve final concentrations of $0 \%, 5 \%, 10 \%, 15 \%$ and $20 \%(\mathrm{w} / \mathrm{v})$. The mixtures were then incubated at $37^{\circ} \mathrm{C}$ and $150 \mathrm{r} / \mathrm{min}$ for $48 \mathrm{~h}$. Then, the BA degradation rates were determined.

\section{Effects of temperature on the BA degradation rates}

The washed cells were resuspended in $0.05 \mathrm{~mol} / \mathrm{L}$ phosphate buffer solution ( $\mathrm{pH} 7.0,10 \% \mathrm{NaCl}$ concentration) supplemented with $500 \mathrm{mg} / \mathrm{L}$ of each BA. The cell concentration was adjusted to $\mathrm{OD}_{600 \mathrm{~nm}}=0.8$. The mixtures were then incubated at different temperatures $(25,30,37$, 40 and $45^{\circ} \mathrm{C}$ ) for $48 \mathrm{~h}$ with shaking at $150 \mathrm{r} / \mathrm{min}$. The BA degradation rates were determined.

\section{Effects of $\mathrm{pH}$ on $\mathrm{BA}$ degradation rates}

The washed cells were resuspended in sterile physiological saline with $\mathrm{pH}$ values of 5.0, 6.0, 7.0, 8.0, and 9.0, containing four BAs each at a concentration of $500 \mathrm{mg} / \mathrm{L}$ and salt concentration of $10 \%$. We adjusted the concentration of the bacterial suspension to $\mathrm{OD}_{600}$ $\mathrm{nm}=0.8$, and then incubated at $37^{\circ} \mathrm{C}$ and $150 \mathrm{r} / \mathrm{min}$ for $48 \mathrm{~h}$. The BA degradation rates were determined.

\section{Effects of ethanol concentration on the BA degradation rates}

The washed cells were resuspended in $0.05 \mathrm{~mol} / \mathrm{L}$ phosphate buffer ( $\mathrm{pH} 7.0,10 \% \mathrm{NaCl}$ concentration) supplemented with $500 \mathrm{mg} / \mathrm{L}$ of each BA. The cell concentration was adjusted to $\mathrm{OD}_{600 \mathrm{~nm}}=0.8$. Ethanol was added to achieve final concentrations of $0 \%, 2 \%, 5 \%$, $10 \%$ and $15 \%(\mathrm{w} / \mathrm{v})$. The mixtures were then incubated at $37{ }^{\circ} \mathrm{C}$ and $150 \mathrm{r} / \mathrm{min}$ for $48 \mathrm{~h}$. The BA degradation rates were determined.

\section{Degradation characteristics of biogenic amines Ways of strain to degrade the BAs}

The washed cells (Xu et al. 2016) were resuspended in $0.05 \mathrm{~mol} / \mathrm{L}$ phosphate buffer solution $(\mathrm{pH} 7.0,10 \%$ $\mathrm{NaCl}$ concentration) with an $\mathrm{OD}_{600 \mathrm{~nm}}=0.8$. A half volume of the suspension was used as the active cells group. The other half volume of the suspension was sterilized at $121{ }^{\circ} \mathrm{C}$ for $20 \mathrm{~min}$ and used as the dead cells group. BAs were added to both groups to achieve a final concentration of $500 \mathrm{mg} / \mathrm{L}$ of each BA. The mixtures were then incubated at $37^{\circ} \mathrm{C}$ and $150 \mathrm{r} / \mathrm{min}$ for $48 \mathrm{~h}$. Then, we could calculate the action mode of the strains to degrade BAs.

\section{Localization of $\mathrm{AOS}$}

The culture was centrifuged at $8000 \mathrm{xg}$ for $10 \mathrm{~min}\left(4{ }^{\circ} \mathrm{C}\right)$ and the supernatant was collected as the 'extracellular fraction'. The cells were washed twice with $0.05 \mathrm{~mol} / \mathrm{L}$ phosphate buffer ( $\mathrm{pH}$ 7.0) and resuspended in phosphate buffer ( $\mathrm{pH} 7.0,10 \% \mathrm{NaCl}$ concentration). The cell suspension was collected as the 'whole cells'. We ground the cell suspension with a tissue grinder. The mixture was centrifuged at $10,000 \mathrm{~g}$ for $30 \mathrm{~min}\left(4{ }^{\circ} \mathrm{C}\right)$ and the supernatant was collected as the 'intracellular fraction. The sediment was washed twice with $0.05 \mathrm{~mol} / \mathrm{L}$ phosphate buffer $(\mathrm{pH}$ 7.0) and resuspended in $0.05 \mathrm{~mol} / \mathrm{L}$ phosphate buffer (pH 7.0, 10\% NaCl concentration), which referred to the 'cell membrane fraction'. The BAs were added to the four groups to achieve a final concentration of $500 \mathrm{mg} / \mathrm{L}$ of each BA. All of the mixtures were incubated at $37^{\circ} \mathrm{C}$ 
and $150 \mathrm{r} / \mathrm{min}$ for $48 \mathrm{~h}$. The BA degradation rates of each group were determined (Tapingkae et al. 2010).

\section{Safety assessment of the strains}

The susceptibility of the strains to 8 clinically important antibiotics [chloramphenicol, clindamycin, erythromycin, ampicillin, kanamycin, streptomycin, tetracycline and ciprofloxacin: selected based on the EFSA guidelines for testing the antimicrobial susceptibility of the Bacillus species (EFSA 2012)] (Dina et al. 2020). The strains (Kanjan and Sakpetch 2020) were tested for hemolytic activity by streaking on blood agar ( $5 \% \mathrm{v} / \mathrm{v}$ sheep blood). The hemolytic reaction was detected by the appearance of a clear zone ( $\beta$-hemolysis: complete lysis of red blood cells), a greenish zone ( $\alpha$-hemolysis: conversion of red blood cell hemoglobin to methemoglobin) or the absence of any zone ( $\gamma$-hemolysis: no hemolytic activity) around the colony developing on the blood agar. The formation and measurement of biofilms mainly refers to previously reported experimental processes (Wang et al. 2012; Stepanovic 2000).

\section{Application analysis of BA-degrading strains Degradation of BAs in Gssp by strain}

We added $500 \mu \mathrm{L}$ of inoculum separately to a $100 \mathrm{~mL}$ Erlenmeyer flask containing $50 \mathrm{~g}$ of Gssp (Weihai, Shandong). The control sample was incubated with $500 \mu \mathrm{L}$ of sterile distilled water instead of the starter. The mixture was then incubated at $37{ }^{\circ} \mathrm{C}$ for 10 days. The degradation rates of the BAs were determined by HPLC, and the experiment was conducted in triplicate.

\section{Effects of the strains on the flavor of the Gssp}

We added $200 \mu \mathrm{L}$ of inoculum separately to a $50 \mathrm{~mL}$ centrifuge tube containing a $20 \mathrm{~mL}$ Gssp sample obtained from Weihai, Shandong. Control samples were cultured with $200 \mu \mathrm{L}$ sterile distilled water instead of the starter. Then, the mixture was incubated at $37{ }^{\circ} \mathrm{C}$ for $10 \mathrm{~d}$. The PEN3 type electronic nose sensor was used to test the sample. Each chemical sensor corresponds to a different type of sensitive substance. The response signal of the electronic nose sensor is basically stable after $50 \mathrm{~s}$. In this study, $58 \mathrm{~s}$ was selected as the signal acquisition time point, and each group of samples was measured 6 times in parallel.

\section{Degradation of BAs in other fermentation products by strains}

Add $500 \mu \mathrm{L}$ of inoculum separately to a $100 \mathrm{~mL}$ Erlenmeyer flask containing $50 \mathrm{~g}$ of cheese(SUKI,Germany) and natto(Japan) samples. The control sample was incubated with $500 \mu \mathrm{L}$ of sterile distilled water instead of the starter. The mixture was then incubated at $37^{\circ} \mathrm{C}$ for
10 days. The degradation rates of BAs were determined by HPLC, and the experiment was in triplicate.

\section{Determination of BAs}

The contents of the BAs were determined by HPLC (Sang et al. 2020b). An aliquot $(20 \mathrm{~mL})$ of $10 \%$ trichloroacetic acid (TCA) was added to $5 \mathrm{~g}$ of the sample to be tested, and the mixture was homogenized using a vortex mixer and then allowed to react at $4{ }^{\circ} \mathrm{C}$ for $2 \mathrm{~h}$. After that, the mixture was centrifuged at $3000 \mathrm{~g}$ and $4{ }^{\circ} \mathrm{C}$ for $10 \mathrm{~min}$. The supernatant was collected, whereas the residue was extracted again with an equal volume of $10 \%$ TCA and centrifuged as before. To measure $1 \mathrm{~mL}$ of bacterial solution, $9 \mathrm{~mL}$ of $10 \%$ TCA vortex was added, it was incubated at $4{ }^{\circ} \mathrm{C}$ for $2 \mathrm{~h}$, then centrifuged at $3000 \mathrm{~g}$ at $4{ }^{\circ} \mathrm{C}$ for $10 \mathrm{~min}$. We mixed $400 \mu \mathrm{L}$ of the abovementioned supernatant with $80 \mu \mathrm{L}$ of $2 \mathrm{~mol} / \mathrm{L} \mathrm{NaOH}, 120 \mu \mathrm{L}$ of saturated $\mathrm{NaHCO}_{3}$ and $800 \mu \mathrm{L}$ of dansulfonyl chloride $(10 \mathrm{mg} /$ $\mathrm{mL})$. The residual dansulfonyl chloride was removed by adding $50 \mu \mathrm{L}$ of ammonia after $40 \mathrm{~min}$ in a water bath at $45{ }^{\circ} \mathrm{C}$, followed by further incubation at room temperature for $30 \mathrm{~min}$. This was followed by the addition of 550 $\mathrm{L}$ of acetonitrile, and it was centrifuged for $5 \mathrm{~min}$ at $4{ }^{\circ} \mathrm{C}$ and $3000 \mathrm{~g}$. The supernatant was filtered twice through a $0.22 \mu \mathrm{m}$ filter before the determination of BAs.

\section{Statistical analysis}

All statistical analyses were based on data from duplicate samples from experiments that were repeated three times. One-way analysis of variance (ANOVA) using SPSS 19.0 was used to determine whether differences between the strains were significant. The means were compared with Duncan's multiple comparisons test, and $\mathrm{p}<0.05$ was considered to indicate statistical significance.

\section{Results}

\section{Screening of BA-degrading strains in Gssp}

Early in the laboratory, a total of 442 strains of halophilic bacteria were identified in the Gssp, and they were classified into 46 genera and 103 species based on their $16 \mathrm{~S}$ rRNA sequences (Sang et al. 2020a). Inoculation aminenegative strains can reduce the accumulation of BAs from the source, and a decarboxylase negative result is indicated with a yellow color. As shown in the Additional file 1: Table S1, 37 strains were screened out.

AOs play a key role in the degradation process of BAs, and according to whether the colonies turned blue, 11 strains with strong AO ability were selected (Table 1, Fig. 1a, b). The degradation ability of these 11 strains is illustrated in Fig. 1c, and Virgibacillus halodenitrificans (G25) and Virgibacillus pantothenticus (G38) have the highest degradation rates among them. Therefore, follow-up studies were carried out on these two strains. 
Table 1 Sequence number of BA degrading bacteria

\begin{tabular}{ll}
\hline Number & Strains \\
\hline 1 & Oceanobacillus picturae \\
2 & Bacillus zhangzhouensis \\
3 & Bacillus safensis \\
4 & Virgibacillus halodenitrificans \\
5 & Oceanobacillus oncorhynchi \\
6 & Pantoea eucrina \\
7 & Virgibacillus sp. \\
8 & Virgibacillus pantothenticus \\
9 & Bacillus cereus \\
10 & Oceanobacillus caeni \\
11 & Oceanobacillus iheyensis \\
\hline
\end{tabular}

\section{Degradation of $\mathrm{BAs}$ under different conditions}

The degradation rates of the BAs reached the maximum, which also indicates that the activity of AOs is the strongest at this time. The effect of $\mathrm{NaCl}$ concentration is shown in Fig. 2a, and with an increase in $\mathrm{NaCl}$ concentration, the degradation rates of the BAs first increases and then decreases. The influence of temperature and $\mathrm{pH}$ on $\mathrm{AO}$ activity (Fig. 2b, c), they can be seen the best activity of AOs are at $37^{\circ} \mathrm{C}$ and in the range of $\mathrm{pH}$ 6.0-8.0. The affect of ethanol concentration on the AOs is shown in Fig. 2d, the degradation rates of the BAs decreased rapidly with an increase in ethanol concentration, when the ethanol concentration reaches $10 \%$, the degradation ability of most BAs is reduced by more than $50 \%$.

\section{Degradation characteristics of biogenic amines}

To determine whether the BA removal ability was due to adsorption or biological action, the removal rates of four BAs by dead cells and living cells of the strains were compared. The results are shown in Fig. 3a, the living cells showed high degradation ability on the four kinds of BAs, while the dead cells showed only very weak degradation ability on the four kinds of BAs. Thus, G25 and G38 removed four BAs mainly by their biological action.

Then, we determined where the AOs were located. It has been reported that AOs are mainly distributed on the cell membrane (Lizcano et al. 1998) or in the cytoplasmic space (Lee et al. 2008). As shown in Fig. 3b, BA degradation activity was not detected in either the extracellular or the intracellular fraction. The membrane fraction exhibited high degradation activity, although it was slightly lower than that of the whole cells. This might be attributed to partial AO destruction by broken tissue. Thus, it can be concluded that the AOs of G25 and G38 were mainly located on the cell membrane.

\section{Safety assessment of the strains}

The safety attributes toward antibiotic susceptibility, biofilm activity and hemolytic activity were evaluated. As per EFSA (2012), the susceptibility of the strain to a certain range of antimicrobials of human and veterinary importance should be evaluated if the bacterial product needs to be used as an additive (Hae et al. 2017). It was found that these two strains were sensitive to the antibiotics analyzed and as per the MIC data, all of the values were lower than the breakpoint limit values as mentioned a
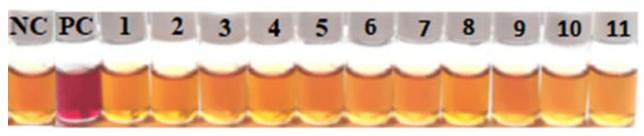

$\mathbf{b}$

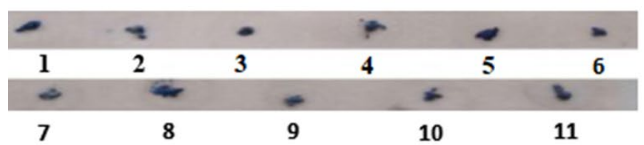

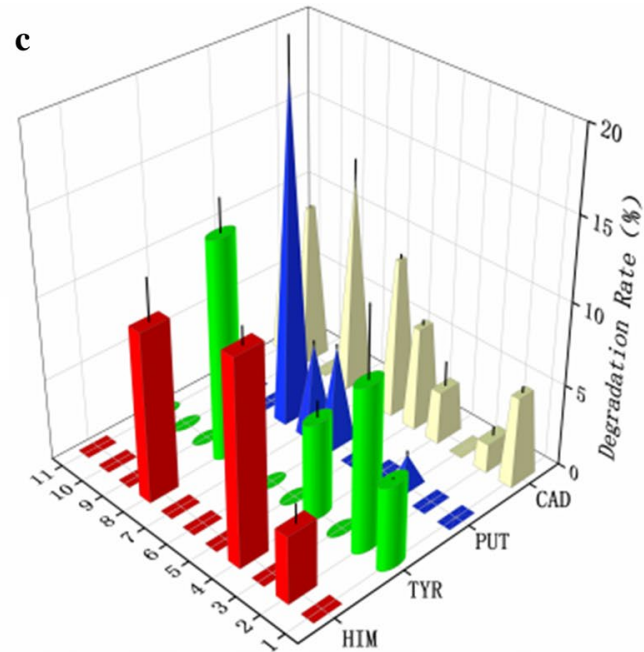

Fig. 1 Screening of BA-degrading strains in Gssp (the numbers in the figure are the order of the strains): a Decarboxylase activity, negative reaction: yellow, the negative control (NC) is a medium without any bacterial cells; positive reaction: purple, the positive control (PC) strain is Bacillus clausii. $\mathbf{b}$ $\mathrm{AO}$ activity. $\mathbf{c}$ Evaluation of BA degradability, data are the means \pm standard deviations from three determinations 


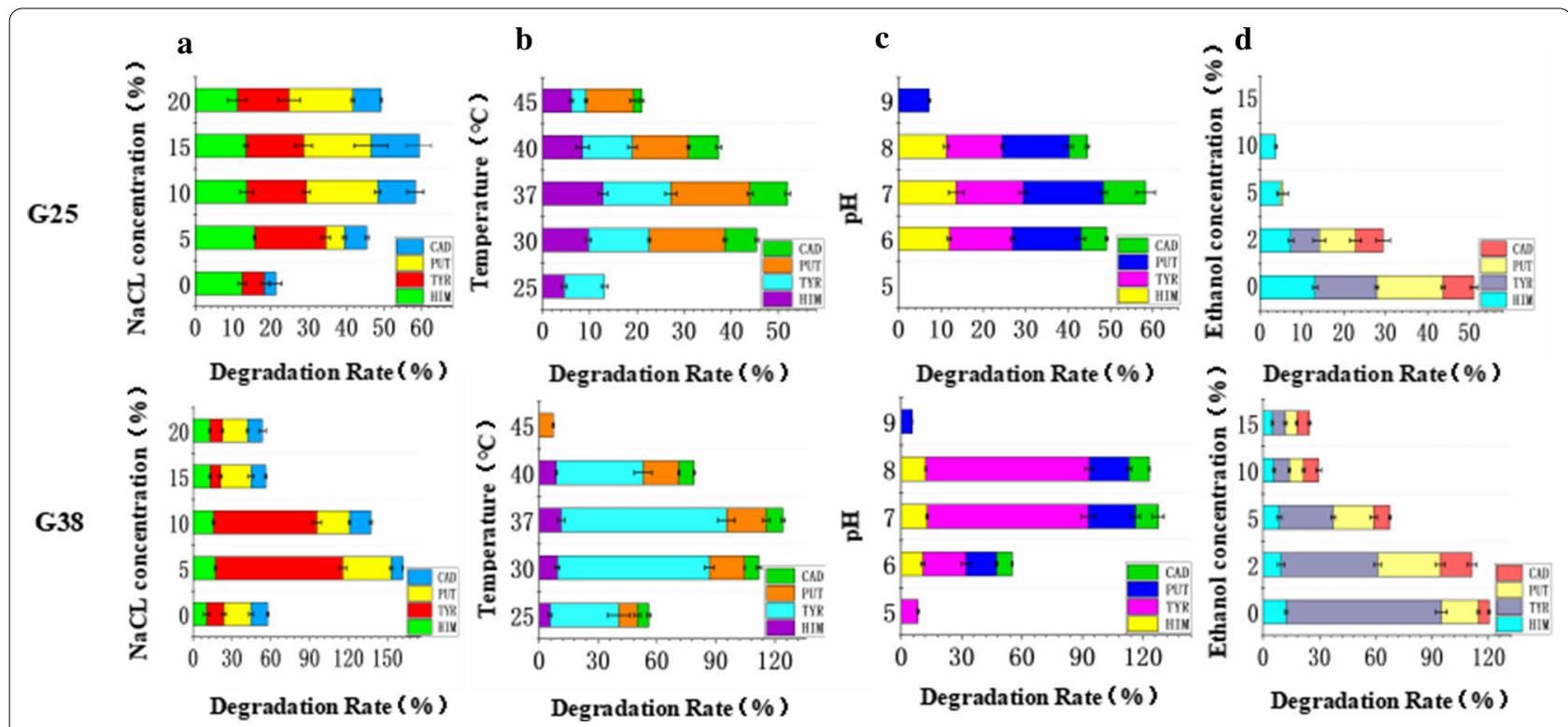

Fig. 2 Degradation of BAs under different conditions, data are the means \pm standard deviations from three determinations: a NaCl concentration. b Temperature. $\mathbf{c}$ pH. d Ethanol concentration

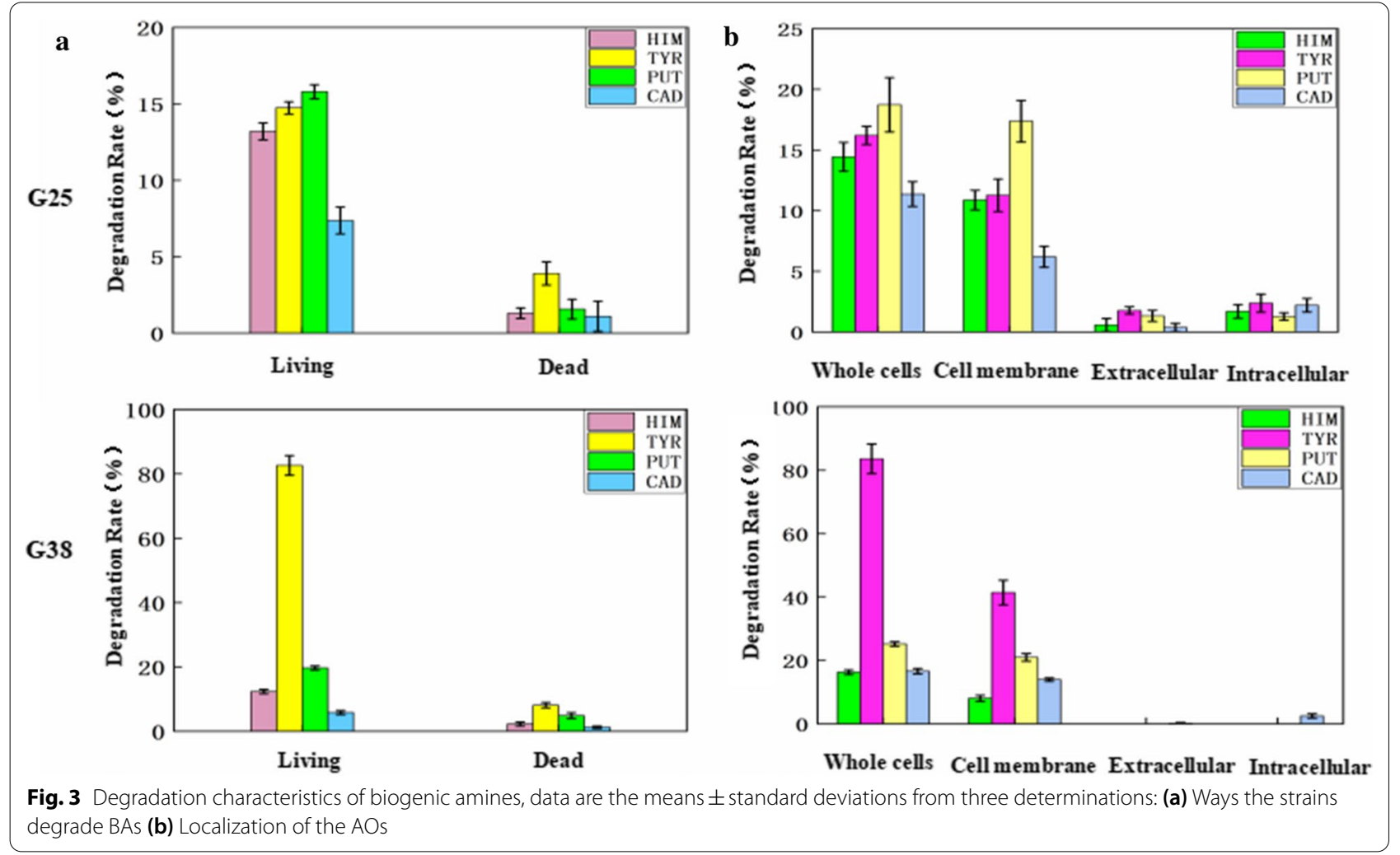

in EFSA (2012), as shown in Table 2. Biofilms are an organized and functional bacterial population. When bacteria form biofilms, their resistance to antibiotics will increase (Naicker 2016). As seen from Table 3, G25 and G38 showed negative results for biofilm formation ability. Hemolytic bacteria can easily cause hemolysis, leading to 
Table 2 Minimum inhibitory concentrations for eight antibiotics tested against the strains

\begin{tabular}{lllll}
\hline \multirow{2}{*}{ Antibiotic } & \multicolumn{3}{l}{ Minimum Inhibitory Concentration (mg/L) } \\
\cline { 2 - 4 } & $\begin{array}{l}\text { MIC break } \\
\text { points }\end{array}$ & \multicolumn{2}{l}{ Test sample } & Interpretation \\
\cline { 3 - 4 } & & G25 & G38 & \\
\hline Chloramphenicol & 8 & 8 & 8 & $\mathrm{~S}$ \\
Clindamycin & 4 & 0.5 & 4 & $\mathrm{~S}$ \\
Erythromycin & 4 & 0.5 & 4 & $\mathrm{~S}$ \\
Kanamycin & 4 & 0.5 & 1 & $\mathrm{~S}$ \\
Streptomycin & 8 & 1 & 2 & $\mathrm{~S}$ \\
Tetracycline & 8 & 2 & 1 & $\mathrm{~S}$ \\
Ampicillin & 4 & 0.5 & 0.5 & $\mathrm{~S}$ \\
Ciprofloxacin & 4 & 0.5 & 4 & $\mathrm{~S}$ \\
\hline
\end{tabular}

Table 3 Biofilm activity of BA degrading bacteria

\begin{tabular}{llll}
\hline Control & \multicolumn{2}{l}{ Biofilm Determination } & \\
\cline { 2 - 3 } & Test Sample & Activity \\
\hline ODc & G25 & G38 & \\
\hline 0.04640 & $0.0061 \pm 0.0017$ & $0.01655 \pm 0.0049$ & Negetive
\end{tabular}

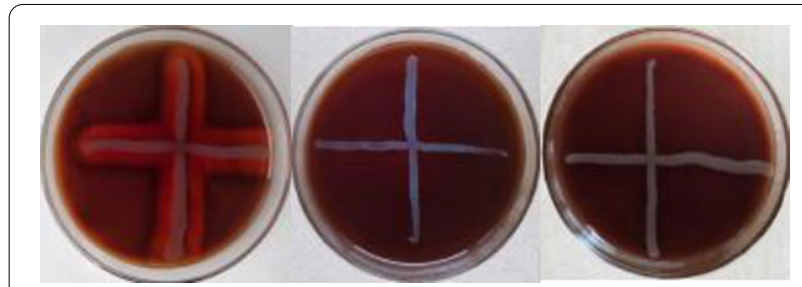

Fig. 4 Hemolytic activity. From left to right, the positive control: Bacillus Zhangzhouensis, G25, G38 sepsis. We found G25 and G38 did not induce hemolysis when plated on sheep blood agar ( $\gamma$-hemolysis), whereas Bacillus zhangzhouensis, as a positive control, induced $\beta$-hemolysis presenting with a clear zone around its colony (Fig. 4). Therefore, the combination of antibiotic susceptibility, biofilm activity and hemolytic activity test results can preliminarily determine that these strains are safe and have potential application prospects.

\section{Application analysis of BA-degrading strains}

G25 and G38 might be potential candidates for controlling BAs due to their low BA-producing ability and high BA-degrading ability. Because the mixed culture of the strains has an unsatisfactory effect on the degradation of BAs (The results are not shown), the strains were cultured separately. To evaluate the BA degradation abilities of G25 and G38, we added $500 \mu \mathrm{L}$ of inoculum separately to an Erlenmeyer flask containing $50 \mathrm{~g}$ of Gssp, then cultured it at $37{ }^{\circ} \mathrm{C}$ for 10 days. We determined the salt content and $\mathrm{pH}$ value of the Gssp sample to be $23.47 \% \pm 1.68 \%(\mathrm{w} / \mathrm{v})$ and $6.98 \pm 0.14$. The control sample without inoculation of strains showed the highest BA content (HIM: $17.72 \pm 0.62 \mathrm{mg} / \mathrm{kg}$, TYR: $26.30 \pm 0.96 \mathrm{mg} / \mathrm{kg}$, PUT: $52.60 \pm 0.69 \mathrm{mg} / \mathrm{kg}$, and CAD: $64.42 \pm 0.22 \mathrm{mg} / \mathrm{kg}$ ), which was due to fermentation of the native microbes in the fresh grasshopper sub shrimp. The degradation rates of the BAs were analyzed (Fig. 5a). G25 degraded $11.1 \%$ of HIM, $11.3 \%$ of TYR, $15.5 \%$ of PUT and $4.1 \%$ of CAD, while G38 significantly degraded $10.1 \%$ of HIM, $21.8 \%$ of TYR, $18.1 \%$ of PUT and $5.0 \%$ of CAD.

The dominant excellent flavor of Gssp is broad-methane, aromatic, broad-alcohol, etc. However, at the same time, the flavor substances of Gssp also contain some a

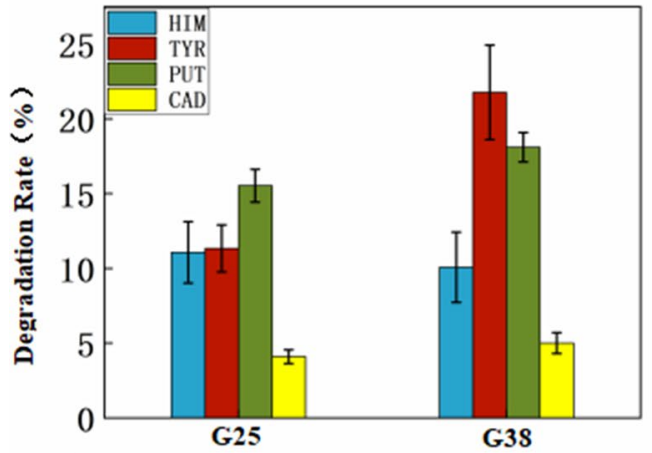

$\mathbf{b}$

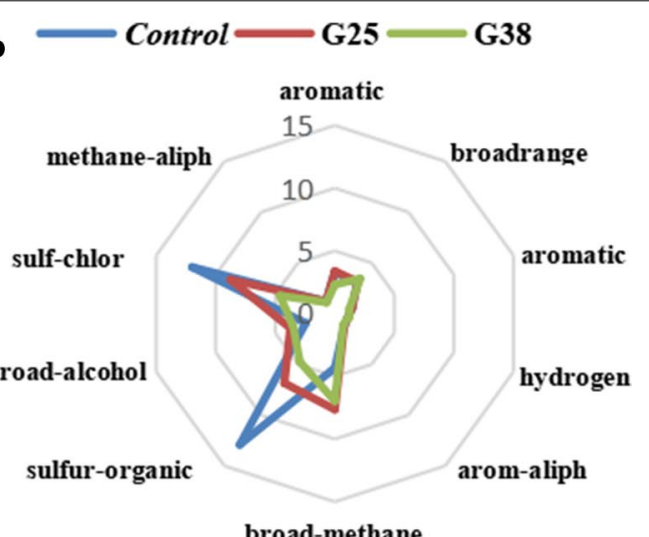

b

broad-methane

Fig. 5 Application analysis of BA-degrading strains, data are the means \pm standard deviations from three determinations: a Degradation of BAs in Gssp by strains. $\mathbf{b}$ Effects of strains on the flavor of Gssp 
unfavorable substances, such as sulfur-organic and sulf-chlor, etc. When selecting starters, it is necessary to evaluate whether they have an adverse effect on the flavor or damage the taste of the products. We added $200 \mu \mathrm{L}$ of inoculum (G25 and G38) separately to the centrifuge tube containing $20 \mathrm{~mL}$ Gssp and incubated it at $37^{\circ} \mathrm{C}$ for $10 \mathrm{~d}$. As seen from Fig. 5b, compared with the control, the broad-methane and broad-alcohol signal response value of the starter groups increased. For the sulfur-organic and sulf-chlor, the response values in the starter groups were significantly reduced, with G25 and $\mathrm{G} 38$ reduced by $39 \%$ and $65 \%$, respectively.

In order to evaluate the degradation rates of BAs in other fermented products by strains, cheese and natto with higher BAs content were selected as the research objects. Evaluated the BAs degradation abilities of G25 and G38, add $500 \mu \mathrm{L}$ of inoculum separately to Erlenmeyer flask containing $50 \mathrm{~g}$ of cheese or natto sample, after culture at $37^{\circ} \mathrm{C}$ for $10 \mathrm{~d}$. Determine the salt content and $\mathrm{pH}$ value of the cheese sample is $9.25 \% \pm 0.87 \%(\mathrm{w} / \mathrm{v})$ and $6.98 \pm 0.14$. For natto, sodium chloride is not added during processing and the $\mathrm{pH}$ value is $7.06 \pm 0.27$. The content of each $\mathrm{BA}$ in cheese are $17.82 \pm 1.07 \mathrm{mg} / \mathrm{kg}$ of $\mathrm{HIM}, 51.30 \pm 1.48 \mathrm{mg} / \mathrm{kg}$ of TYR, and $21.12 \pm 1.81 \mathrm{mg} / \mathrm{kg}$ of PUT. The degradation rates of BAs in cheese were analyzed (Fig. 6a), G25 degraded $32.50 \%$ of HIM, $15.67 \%$ of TYR, and $23.70 \%$ of PUT; G38 significantly degraded $22.17 \%$ of HIM, $45.43 \%$ of TYR, and $30.83 \%$ of PUT. The content of each BA in natto are $17.16 \pm 3.01 \mathrm{mg} / \mathrm{kg}$ of HIM, $37.52 \pm 2.75 \mathrm{mg} / \mathrm{kg}$ of TYR, $17.62 \pm 0.74 \mathrm{mg} / \mathrm{kg}$ of PUT, and $9.63 \pm 0.57 \mathrm{mg} / \mathrm{kg}$ of CAD. The degradation rates of BAs in natto were analyzed (Fig. 6b), G25 degraded $23.20 \%$ of HIM, $14.23 \%$ of TYR, $10.50 \%$ of PUT, and $10.40 \%$ of CAD; G38 significantly degraded $12.70 \%$ of HIM, $24.87 \%$ of TYR, $26.67 \%$ of PUT, and $18.23 \%$ of CAD. In summary, these two starters still have high degradation rates for other fermentation products, they can also be used as starters in products other than Gssp.

\section{Discussion}

Virgibacillus spp. are commonly found in fermented foods, but they appear to have no significant correlation with HIM, TYR, PUT or CAD, and it is the one of five most abundant genera of all bacteria in Gssp (Sang et al. 2020b). Many scholars have shown that the selected Virgibacillus spp. species could be used as starters for fermented aquatic products. For example, fish sauce samples inoculated with Virgibacillus sp. SK37 showed the potential to improve quality in terms of volatile compounds, glutamic acid content and overall acceptability (Udomsil et al. 2017). Virgibacillus halodenitrificans MSK-10P is a good candidate for further investigation for use in fermented shrimp paste to assess its technological performance as an autochthonous starter culture (Kumaunang et al. 2019).

G25 and G38 retained relatively high BAs degradation activity with an $\mathrm{NaCl}$ concentration ranging from 5 to $10 \%$ (Fig. 2a), this is because a certain amount of sodium chloride will change the permeability of the cell membrane and allow the AOs to penetrate more, when it exceeds a certain value, it will inhibit their permeability. For example, although SWA25 (Ying et al. 2016) is a salt-tolerant bacterium, the addition of $\mathrm{NaCl}$ concentration can significantly inhibit its BA degradation activity. Virgibacillus spp. had the highest degradation rate of BAs in the temperature at $37^{\circ} \mathrm{C}$ (Fig. 2b), this may be because, on the one hand, a low temperature environment reduced the microbial activity, and on the other hand, the $\mathrm{AO}$ activity at high temperature is being strongly inhibited. This is consistent with the results of other relevant studies. For example, halotolerant Staphylococcus carnosus FS19 had the best ability to degrade HIM at $40{ }^{\circ} \mathrm{C}$ with a
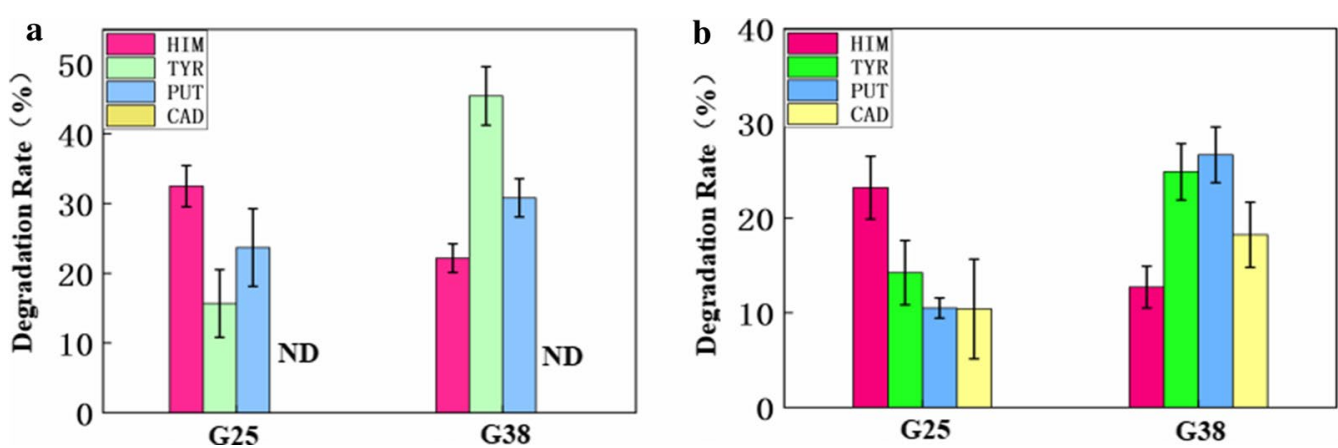

Fig. 6 Degradation of BAs in other fermentation products by strains, data are the means \pm standard deviations from three determinations: a Degradation of BAs in cheese by strains. $\mathbf{b}$ Degradation of BAs in natto by strains 
degradation rate of $23.5 \%$, and when the temperature was increased to $45{ }^{\circ} \mathrm{C}$ and $50{ }^{\circ} \mathrm{C}$, the degradation rates were only $6.1 \%$ and $3.3 \%$ (Zaman et al. 2014). Brevibacillus sp. SK35 had the highest HIM degradation rate at $35^{\circ} \mathrm{C}$ (Sinsuwan et al. 2010). The highest BAs degrading activity were observed in the $\mathrm{pH}$ range of 6.0-8.0 (Fig. 2c), which may be because the strains degrade BAs mainly through AOs, and acid degradation plays a secondary role. At the $\mathrm{pH}$ values of 5.0 and 9.0, the degradation ability of the BAs are reduced or lost, which may be caused by the inhibition of the activity of microorganisms and AOs in an acidic or alkaline environment. Similar to this result, D05-1 had the highest HIM degradation ability (100\%) at pH 7.0, but it slightly inhibited the degradation ability of HIM under acid or alkaline conditions (Lee et al. 2015). The inhibitory effect of ethanol on AOs (Fig. 2d), Virgibacillus spp. can only play a better role in the degradation of BAs in the ethanol system with a concentration of less than $2 \%$, this result is consistent with previous research results that adding $12 \%$ ethanol reduced the degradation ability of $L$. casei IFI-CA 52 on HIM by approximately 70\% (García Ruiz et al. 2011).

BA removal ability of G25 and G38 are mainly due to biodegradation, not adsorption or bioaccumulation (Fig. 3a) and AOs exist on the cell membrane (Fig. 3b). The activity of the AOs was affected by the $\mathrm{NaCl}$ concentration, temperature, $\mathrm{pH}$ and ethanol concentration. In particular, the concentration of $\mathrm{NaCl}$ can change the activity of AOs since at a suitable concentration, it can change the permeability of the cell membrane and increase the amount of AOs.

G25 and G38 can effectively remove BAs from Gssp (Fig. 5a), however, the complex environmental conditions of fermented foods, mainly high-salt environments, can inhibit the growth and reproduction of microorganisms while also reducing the activity of most AOs (Naila et al. 2012). Virgibacillus spp. can improve the flavor of Gssp (Fig. 5b), this is consistent with the findings of other scholars, Fonseca et al. (2013) proved that the overall acceptance of the final products inoculated with any of the starter cultures assayed was significantly higher than that of the uninoculated control batch.

In summary, Virgibacillus spp. species have potential uses as starters in a food model of fermented aquatic products. Two strains of G25 and G38 were found to be non-BA producing and actually degraded them. BAs are degraded mainly by AOs distributed on the cell membrane instead of by physical adsorption or bioaccumulation. Environmental factors have a strong impact on the activity of AOs. G25 and G38 can improve the flavor and quality of Gssp, in addition, these two strains were also found to be able to degrade the BAs in cheese and natto. G25 and G38 meet the relevant safety standards as starters, and may be used as effective biological control agents in fermented products to degrade the undesired accumulation of toxic BAs during product manufacturing. This research provides a certain theoretical basis for the selection and development of starters and the quality improvement of fermented products.

\section{Supplementary Information}

The online version contains supplementary material available at https://doi. org/10.1186/s13568-021-01186-9.

Additional file 1: Table S1. 37 decarboxylase negative strains

\section{Abbreviations}

BA: Biogenic amine; G25: Virgibacillus halodenitrificans; G38: Virgibacillus pantothenticus; Gssp: Grasshopper sub shrimp paste; AO: Amine oxidase; HIM: Histamine; TYR: Tyramine; PUT: Putrescine; CAD: Cadaverine; LB: Luria-Bertani; HPLC: High-performance liquid chromatography.

\section{Acknowledgements}

This work was supported by the National Key R \& D Program of China (2017YFC1600403) and the Liaoning Province's Program for Promoting Liaoning Talents (XLYC1808034).

\section{Authors' contributions}

YZ, Data curation, Writing Original draft, Writing Review \& Editing. XS, Strains provider for this research. HH, Supervision. JB, Writing Review \& Editing. GZ, Supervision. HH, Conceptualization, Resources, Writing Review \& Editing. All authors read and approved the final manuscript.

\section{Funding}

This work was supported by the National Key R \& D Program of China (2017YFC1600403) and the Liaoning Province's Program for Promoting Liaoning Talents (XLYC1808034).

\section{Availability of data and materials}

I would like to declare on behalf of my co-authors that the work described was original research that has not been published previously, and not under consideration for publication elsewhere, in whole or in part. All the authors listed have approved the manuscript that is enclosed.

\section{Ethics approval and consent to participate}

Not applicable.

\section{Consent for publication}

Not applicable.

\section{Competing interests}

The authors declare that they have no conflict of interest.

\section{Author details}

${ }^{1}$ School of Food Science and Technology, Dalian Polytechnic University, No.1, Qinggongyuan, Ganjingzi District, Dalian 116034, China. ${ }^{2}$ Liaoning Key Lab for Aquatic Processing Quality and Safety, Dalian Polytechnic University, No.1, Qinggongyuan, Ganjingzi District, Dalian 116034, China.

Received: 20 January 2021 Accepted: 1 February 2021

Published online: 10 February 2021

\section{References}

Callejón S, Sendra R, Ferrer S, Pardo I (2014) Identification of a novel enzymatic activity from lactic acid bacteria able to degrade biogenic amines in wine. Appl Microbiol Biot 98:185-198. https://doi.org/10.1007/s0025 3-013-4829-6 
Callejón S, Sendra R, Ferrer S, Pardo I (2016) Cloning and characterization of a new laccase from lactobacillus plantarum J16 CECT 8944 catalyzing biogenic amines degradation. Appl Microbiol Biot 100:3113-3124. https ://doi.org/10.1007/s00253-015-7158-0

Cheng S, Xu Y, Lan X (2020) Isolation, characterization, and application of biogenic amines degrading strains from fermented food. J Food Saf. https ://doi.org/10.1111/jfs.12716

Dina B, Saroj AK, Gupta AK (2020) Genome based safety assessment for Bacillus coagulans strain LBSC (DSM 17654) for probiotic application. Int J Food Microbiol 318:108523. https://doi.org/10.1016/j.ijfoodmicro.2020.108523

EFSA, 2012. EFSA Panel on Additives and Products or Substances used in Animal Feed (FEEDAP); Guidance on the assessment of bacterial susceptibility to antimicrobials of human and veterinary importance (Question no EFSA-Q-2011-01108, adopted: 23 May 2012 by European Food Safety Authority). EFSA J. 10, 2740. (10 pp.) doi: https://doi.org/10.2903/j. efsa.2012.2740

Eom JS, Seo BY, Choi HS (2015) Biogenic amine degradation by Bacillus species isolated from traditional fermented soybean food and detection of decarboxylase related genes. J Microbiol Biotechn 25:1519-1527. https://doi. org/10.4014/jmb.1506.06006

Fonseca S, Cachaldora A, María G, Franco I, Carballo J (2013) Effect of different autochthonous starter cultures on the volatile compounds profile and sensory properties of galician chorizo, a traditional spanish dry fermented sausage. Food Control 33:6-14. https://doi.org/10.1016/j.foodc ont.2013.01.040

García Ruiz A, Rompinelli EM, Bartolomé B, Arribas M, Victoria M (2011) Potential of wine-associated lactic acid bacteria to degrade biogenic amines. Int J Food Microbiol 148:115-120. https://doi.org/10.1016/j.ijfoodmicr 0.2011 .05 .009

Gardini F, Özogul Y, Suzzi G, Tabanelli G, Özogul F (2016) Technological factors affecting biogenic amine content in foods: a review. Front Microbiol 7:1218. https://doi.org/10.3389/fmicb.2016.01218

Hae C, Lee C, Gi S (2017) Assessment of Bacillus subtilis SN7 as a starter culture for cheonggukjang, a korean traditional fermented soybean food, and its capability to control bacillus cereus in cheonggukjang. Food Control 73:946-953. https://doi.org/10.1016/j.foodcont.2016.10.015

Kanjan P, Sakpetch P (2020) Functional and safety assessment of Staphylococcus Simulans PMRS35 with high lipase activity isolated from high saltfermented Fish (Budu) for Starter development. LWT 124:109183. https:// doi.org/10.1016/j.Iwt.2020.109183

Kim KH, Lee SH, Chun BH, Jeong SE, Jeon CO (2019) Tetragenococcus halophilus MJ4 as a starter culture for repressing biogenic amine (cadaverine) formation during saeu-jeot (salted shrimp) fermentation. Food Microbiol 82:465-473. https://doi.org/10.1016/j.fm.2019.02.017

Kumaunang M, Sanchart C, Suyotha W, Maneerat S (2019) Virgibacillus halodenitrificans MSK-10P, a potential protease-producing starter culture for fermented shrimp paste (kapi) production. J Aquat Food Prod T 28:877-890. https://doi.org/10.1080/10498850.2019.1652874

Latorre Moratalla ML, Bove Cid S, Aymerich T, Marcos B, Vidal Carou MC, Garriga M (2007) Aminogenesis control in fermented sausages manufactured with pressurized meat batter and starter culture. Meat Sci 75:460-469. https://doi.org/10.1016/J.meatsci.2006.07.020

Lee H-I, Kim YM, Ro YT (2008) Purification and characterization of a copper containing amine oxidase from Mycobacterium sp. strain JC1 DSM 3803 grown on benzylamine. J Biochem 144:107-114. https://doi.org/10.1093/ $\mathrm{jb} / \mathrm{mvn} 047$

Lee Gl, Lee HM, Lee CH (2012) Food safety issues in industrialization of traditional Korean foods. Food Control 24:1-5. https://doi.org/10.1016/j.foodc ont.2011.09.014

Lee YC, Lin CS, Liu FL, Huang TC, Tsai YH (2015) Degradation of histamine by Bacillus polymyxa isolated from salted fish products. J Food Drug Anal 23:836-844. https://doi.org/10.1016/j.jfda.2015.02.003

Lizcano JM, Tipton KF, Unzeta M (1998) Purification and characterization of membrane bound semicarbazide-sen sitive amine oxidase (SSAO) from bovine lung. Biochem J 331:69-78. https://doi.org/10.1042/bj3310069

Lorenzo C, Bordiga M, Pérez álvarez EP, Travaglia F, Arlorio M, Salinas MR (2017) The impacts of temperature, alcoholic degree and amino acids content onBiogenic amines and their precursor amino acids content in red wine. Food Res Int 99:328-335. https://doi.org/10.1016/j.foodres.2017.05.016

Lu L, Xiaoxue W, Zhiyou W, Shouwen C, Ling W, Xuetuan W (2018) Evaluation of the biogenic amines formation and degradation abilities of lactobacillus curvatus from chinese bacon. Front Microbiol 9:1015. https:// doi.org/10.3389/fmicb.2018.01015

Lv X, Li Y, Cui T, Sun M, Bai F, Li X, Li J, Yi S (2020) Bacterial community succession and volatile compound changes during fermentation of shrimp paste from Chinese Jinzhou region. LWT 122:108998. https://doi. org/10.1016/j.lwt.2019.108998

Miguel A, Alvarez MV, Arribas M (2014) The problem of biogenic amines in fermented foods and the use of potential biogenic amine-degrading microorganisms as a solution. Trends Food Sci Tech 29:146-155. https:// doi.org/10.1016/j.tifs.2014.07.007

Naicker PR, Karayem K, Hoek KGP, Harvey J, Wasserman E (2016) Biofilm formation in invasive staphylococcus aureus isolates is associated with the clonal lineage. Microb Pathog 90:41-49. https://doi.org/10.1016/j.micpa th.2015.10.023

Naila A, Flint S, Fletcher G, Bremer P, Meerdink G (2010) Control of biogenic amines in food-existing and emerging approaches[J]. J Food Sci 75:139-150. https://doi.org/10.1111/j.1750-3841.2010.01774.x

Naila A, Flint S, Fletcher GC, Bremer P, Meerdink G (2012) Histamine degradation by diamine oxidase, Lactobacillus and Vergibacillus halodonitrificans Nai18. J Food Process Technol 3:1000158. https://doi.org/10.4172/21577110.1000158

Nakano M, Sato H, Watanabe T, Takano K, Sagane Y (2018) Mining online activity data to understand food consumption behavior: a case of asian fish sauce among japanese consumers. Food Sci Nutr 6:791-799. https://doi. org/10.1002/fsn3.622

Natteewan U, Sureelak R, Joon CY, Yanglin H, Jirawat Y (2011) Use of Tetragenococcus halophilus as a starter culture for flavor improvement in fish sauce fermentation. J Agric Food Chem 59:8401-8408. https://doi.org/10.1021/ jf201953v

Orejana FM, Liston J (2010) Agents of proteolysis and its inhibition in Patis (fish sauce) fermentation. J Food Sci 47:198-203. https://doi. org/10.1111/j.1365-2621.1982.tb11058.x

Phewpan A, Phuwaprisirisan P, Takahashi H, Ohshima C, Keeratipibul S (2019) Microbial diversity during processing of Thai traditional fermented shrimp paste, determined by next Generation sequencing. LWT 122:108989. https://doi.org/10.1016/j.lwt.2019.108989

Sang X, Ma XX, Hao HS, Bi JR, Zhang GL, Hou HM (2020a) Evaluation of biogenic amines and microbial composition in the Chinese traditional fermented food grasshopper sub shrimp paste. LWT 134:109979. https:// doi.org/10.1016/j.lwt.2020.109979

Sang X, Li KX, Zhu YL, Ma XX, Hao HS, Bi JR, Hou HM (2020b) The impact of microbial diversity on biogenic amines formation in grasshopper sub shrimp paste during the fermentation. Front Microbiol 11:782. https://doi. org/10.3389/fmicb.2020.00782

Sinsuwan S, Montriwong A, Rodtong S, Yongsawatdigul J (2010) Biogenic amines degradation by moderate halophile, Brevibacillus sp. SK35. J Biotechnol 150:316. https://doi.org/10.1016/j.jbiotec.2010.09.297

Spano G, Russo P, Lonvaud Funel A, Lucas P, Alexandre H, Grandvalet C (2010) Biogenic amines in fermented foods. Eur J Clin Nutr 64:95-100. https:// doi.org/10.1038/ejen.2010.218

Stepanovic S (2000) A modified microtiter-plate test for quantification of staphylococcal biofilm formation. J Microbiol Meth 40:175-179. https:// doi.org/10.1016/S0167-7012(00)00122-6

Tan Y, Zhang R, Chen G, Wang S, Li C, Yao Xu, Kan J (2019) Effect of different starter cultures on the control of biogenic amines and quality change of douchi by rapid fermentation. LWT 109:395-405. https://doi. org/10.1016/j.lwt.2019.04.041

Tapingkae W, Tanasupawat S, Parkin KL, Benjakul S, Visessanguan W (2010) Degradation of histamine by extremely halophilic archaea isolated from high salt-fermented fishery products. Enzyme Microb Technol 46:92-99. https://doi.org/10.1016/j.enzmictec.2009.10.011

Udomsil N, Chen S, Rodtong S, Yongsawatdigul J (2017) Improvement of fish sauce quality by combined inoculation of Tetragenococcus halophilus MS33 and Virgibacillus sp. SK37. Food Control 73:930-938. https://doi. org/10.1016/j.foodcont.2016.10.007

Wang Q, He Z, Yuejian Hu, Jiang Y, Ma R, Tang Z (2012) Luxs mutant regulation: quorum sensing impairment or Methylation disorder? Sensors 12:6155-6175. https://doi.org/10.3390/s120506176

Wang XH, Ren HY, Wang W, Bai T, Li JX (2015) Evaluation of key factors influencing histamine formation and accumulation in fermented sausages. J Food Saf 35:395-402. https://doi.org/10.1111/jfs. 12187 
Xiaole X, Yi L, Qingwen Z, Yang H, Bin Z (2018) Mixed starter culture regulate biogenic amines formation via decarboxylation and transamination during chinese rice wine fermentation. J Agric Food Chem 66:6348-6356. https://doi.org/10.1021/acs.jafc.8b01134

Xu Y, Liu Y, Binghong X, Dongfeng W, Wei J (2016) Characterisation and application of Halomonas Shantousis SWA25, a halotolerant bacterium with multiple biogenic amine Degradation activity. Food Addit Contam A 33:674-682. https://doi.org/10.1080/19440049.2016.1147086

Zaman MZ, Bakar FA, Jinap S, Bakar J (2011) Novel starter cultures to inhibit biogenic amines accumulation during fish sauce fermentation. Int J Food Microbiol 145:84-91. https://doi.org/10.1016/j.jjfoodmicro.2010.11.031

Zaman MZ, Bakar FA, Selamat J, Bakar J, Ang SS, Chong CY (2014) Degradation of histamine by the halotolerant Staphylococcus Carnosus FS19 isolate obtained from fish sauce. Food Control 40:58-63. https://doi. org/10.1016/j.foodcont.2013.11.031

Zhang Q, Lin S, Nie X (2013) Reduction of biogenic amine accumulation in silver carp sausage by an amine-negative lactobacillus plantarum. Food Control 32:496-500. https://doi.org/10.1016/j.foodcont.2013.01.029

\section{Publisher's Note}

Springer Nature remains neutral with regard to jurisdictional claims in published maps and institutional affiliations.

\section{Submit your manuscript to a SpringerOpen ${ }^{\circ}$ journal and benefit from:}

- Convenient online submission

- Rigorous peer review

- Open access: articles freely available online

- High visibility within the field

- Retaining the copyright to your article

Submit your next manuscript at $\boldsymbol{\nabla}$ springeropen.com 